\title{
Revisão da estratigrafia das rochas da Serra Leste, Província Mineral de Carajás
}

\author{
Carlos Eduardo de Mesquita Barros ${ }^{1}$, Valéria Marinho do Nascimento ${ }^{2}$ \& \\ Carlos Augusto Medeiros Filho
}

\begin{abstract}
Resumo As rochas metabásicas e metassedimentares da Serra Leste estendem-se para oeste até a Serra Norte, passando por Curionópolis e Parauapebas, e apresentam continuidade física até a Serra do Rabo e a Serra Sul. Sendo assim, estas rochas metavulcano-sedimentares pertencem à mesma unidade litoestratigráfica (Supergrupo Itacaiúnas), não sendo aplicável a separação em diferentes grupos (eg. Igarapé Salobo, Igarapé Pojuca, Rio Novo). As rochas metavulcano-sedimentares foram cortadas por dois conjuntos de granitoides, ambos com estruturas que indicam colocação sintectônica a esforços compressivos regionais. A ausência de várias feições petro-estruturais não permite classificar esses granitoides como migmatitos. A idade U-Pb em zircão de 2,85 Ga, publicada no início da década de noventa e atribuída à migmatização, foi aqui reinterpretada como sendo a idade de cristalização de alguns dos granitoides da região, os quais apresentam foliação de direção N30E. Outro conjunto de granitos tem foliação de direção N70-80E e são preliminarmente correlacionados às intrusões ácidas sintectônicas de 2,75 Ga já descritas na região. A intrusão desses granitoides causou extensivo metamorfismo térmico de fácies hornblenda hornfels a clinopiroxênio hornfels nas rochas metavulcanosedimentares encaixantes. Portanto, as rochas do Supergrupo Itacaiúnas são mais antigas que $2,85 \mathrm{Ga}$, a idade de cristalização dos granitoides encaixantes.
\end{abstract}

Palavras-chave: Serra Leste, Serra Pelada, Carajás, greenstone belts, metamorfismo, geologia estrutural.

\begin{abstract}
Stratigraphy of the rocks from the Serra Leste domain, Carajás Mineral
Province: a revision. The structural data of the granitoids exposed in the Serra Leste indicate that their emplacement was coeval with compressive stresses. Xenoliths of metabasic rocks found within the granitic plutons are wrapped around by the syn-magmatic foliation of the latter suggesting that the foliation of the felsic rocks developed during the magmatic cooling. These evidences could discard the hypothesis of migmatization on those granitoids. The U-Pb zircon age of $2.85 \mathrm{Ga}$, attributed to a migmatization event is herein reinterpreted as the age of crystallization of this granitic association. The intrusion of these plutons promoted extensive thermal metamorphic overprinting on the metabasic rocks under amphibole and clinopyroxene hornfels facies. Accordingly the episode of crystallization of the metavolcanic rocks from the Itacaiúnas supergroup necessarily pre-dates the 2.85 Ga age of some granitoid bodies. These metavolcano-sedimentary series are also exposed westward of Parauapebas and Serra Norte domains, in physical continuity with the southernmost Serra do Rabo and Serra Sul domains and, consequently, the supracrustal rocks belong to the same lithostratigraphic sequence (Itacaiúnas supergroup).
\end{abstract}

Keywords: Serra Leste, Serra Pelada, Carajás, greenstone belts, contact metamorphism, stratigraphy.

INTRODUÇÃo Situada na Província Mineral de Carajás (PMC), a Serra Leste tem sido reconhecida como uma área de importância econômica inquestionável, dada à existência de mineralizações de platinóides associadas ao complexo máfico-ultramáfico Luanga (Suita \& Nilson 1988, Diella et al. 1995, Moroni et al. 2001, Cabral et al. 2002), do depósito de ouro de Serra Pelada e pelas ocorrências de manganês supergênico associadas aos calcarenitos manganesíferos e metapelitos da Serra do Sereno (Meireles \& Silva 1988, Tallarico et al. 2000). Além dos estudos de cunho metalogenético, trabalhos de cartografia (Hirata et al.
1982, Araújo et al. 1988) e de geologia estrutural (Lab $\&$ Costa 1995, Pinheiro 1995) foram realizados nesta área.

A relativa escassez de afloramentos e a dificuldade de obter-se a idade de cristalização de rochas metabásicas têm dificultado o estabelecimento preciso de um empilhamento litoestratigráfica para as rochas da Serra Leste. Isto tem causado problemas relativos à definição de unidades litoestratigráficas e à sua distribuição espacial. Um exemplo disto é representado pelos metabasaltos, formações ferríferas e metacherts que são considerados como pertencentes ao

1 - Universidade Federal do Paraná, Departamento de Geologia, Centro Politécnico, Bolsista de Produtividade em Pesquisa do CNPq, Curitiba (PR). E-mail: cadubarros@ufpr.br

2 - UFPA, Programa de Pós-Graduação em Geologia e Geoquímica, Bolsista da CAPES. E-mail: val.m.n@oi.com.br

3 - Vale, Belo Horizonte (MG), Brasil. E-mail: carlos.augusto.medeiros@vale.com 
Grupo Grão Pará (Araújo et al. 1988), ao Grupo Igarapé Pojuca (Docegeo 1988), ao Grupo Rio Novo (Hirata et al. 1982, Meireles et al. 1984, Costa et al. 1990) e ao Complexo Xingu (Vasquez \& Rosa-Costa 2008).

Outro ponto que tem desdobramentos na estratigrafia da Serra Leste diz respeito ao significado de idades obtidas em gnaisses quartzo-feldspáticos considerados como migmatitos (Machado et al. 1991) do embasamento. A caracterização de migmatitos nem sempre se constitui em tarefa simples. Processos de fusão parcial in situ, responsáveis pela formação de migmatitos, dão origem a restitos (melanossoma) mais máficos que o protólito, a porções leucograníticas (leucossoma) geralmente venuladas e mais félsicas que o protólito e porções de composição intermediária (mesossoma) (Ashworth 1985). Critérios que evidenciam estas feições metamórficas nem sempre são inquestionáveis e podem, muitas vezes, ser confundidos com injeções aplíticas e pegmatíticas tardias de câmaras magmáticas sintectônicas. A identificação de migmatitos na Província Mineral de Carajás tem grande importância, dada a dificuldade em se estabelecer domínios que pertençam indiscutivelmente ao conjunto de rochas do embasamento.

Este trabalho tem como objetivos contribuir para o estabelecimento da estratigrafia das rochas da Serra Leste e da história tectono-termal deste importante domínio da Província Mineral dos Carajás. Pretende-se contribuir para o conhecimento das relações temporais entre magmatismo, metamorfismo e deformação na Província Mineral de Carajás. Foram estudadas as feições metamórficas das rochas metabásicas e revistas as estruturas e as idades de rochas gnáissicas quartzofeldspáticas a partir de trabalhos de campo, com ênfase na identificação das estruturas das rochas metabásicas e dos granitoides foliados. Tentou-se estabelecer a cronologia das estruturas e a história metamórfica das rochas supracrustais com o auxílio de dados de campo e de dados microscópicos.

GEOLOGIA REGIONAL A Província Amazônia Central (Tassinari \& Macambira 2004), situada a sudeste do Cráton Amazônico, compreende os terrenos com predomínio de rochas arqueanas. $\mathrm{Na}$ parte meridional da província (Fig. 1) afloram faixas de greenstones (Supergrupo Andorinhas) cortadas por plútons intermediários a ácidos sintectônicos com idades $(\mathrm{Pb}-\mathrm{Pb}$ evaporação de zircão) que variam de $\sim 2,95 \mathrm{Ga}$ (Arco Verde, Guarantã) a 2,87 Ga (Parazônia, Mogno, Rio Maria, Caracol, Xinguara) (Macambira \& Lafon 1995, Althoff et al. 2000, Leite et al. 2004, Dall'Agnol et al. 2006).

Em direção ao norte (Fig. 1), ocorrem granulitos (Pium) com 3,0 Ga (SHRIMP em zircão) (Pidgeon et al. 2000), além de extensas sequências (Rio Novo, Supergrupo Itacaiúnas) de rochas metabásicas (Docegeo 1988, Araújo et al. 1988) com formações ferríferas e metacherts associados.

Gnaisses quartzo-feldspáticos expostos em uma pedreira, em atividade, foram considerados como pertencentes ao embasamento e teriam sido submetidos a uma fase de migmatização. A idade $\mathrm{U}-\mathrm{Pb}$



Figura 1 - Mapa de localização da área de estudo e Mapa geológico esquemático da Província Mineral de Carajás (Vasquez \& Rosa-Costa 2008 modificado). 
em zircão de 2,85 Ga (Machado et al. 1991), obtida em fases graníticas leucocráticas interpretadas como leucossomas, foi atribuída ao evento responsável pela migmatização. As estruturas e o significado tectonotermal destas rochas serão discutidos em mais detalhe neste trabalho.

Corpos máfico-ultramáficos (Luanga) de pequena dimensão, mas de grande interesse econômico foram estudados por vários autores (Meireles \& Silva 1988, Suíta \& Nilson 1988). Datações pelo método $\mathrm{U}-\mathrm{Pb}$ em zircão forneceram a idade de 2,76 Ga para este complexo (Machado et al. 1991). Segundo Moroni et al. (2001) as rochas do Supergrupo Itacaiúnas seriam contemporâneas as do Complexo Xingu.

Dentre os granitoides neoarqueanos sintectônicos $(2,74$ a 2,76 Ga) distinguem-se os subalcalinos (Estrela, Serra do Rabo, Planalto), os cálcio-alcalinos de alto potássio (Igarapé Gelado) e os trondhjemíticos (Canaã dos Carajás) (Huhn et al. 1999, Barros et al. 2001, Barbosa 2005, Sardinha et al. 2006, Gomes \& Dall'Agnol 2007, Barros et al. 2009). Pequenos corpos de dioritos foram englobados na Suíte Intrusiva Formiga (Tallarico et al. 2000), a qual foi preliminarmente considerada mais antiga que $2,75 \mathrm{Ga}$.

Arenitos e siltitos (Águas Claras) anquimetamorfisados de idade incerta afloram na Serra dos Carajás (Araújo et al. 1988, Nogueira et al. 1995) e são cortados por diques e sills de gabros hidrotermalizados com idade mínima de 2,7 Ga (Dias et al. 1996).

Os domínios meridional e setentrional da PMC são cortados por vários granitos anorogênicos subalcalinos (eg. Redenção, Bannach, Cigano, Central) de 1,88 Ga (Docegeo 1988, Olszewski et al. 1989, Machado et al. 1991, Dall'Agnol et al. 2005).

Considerações sobre metamorfismo e geologia estrutural da Serra Leste Os trabalhos sobre a evolução estrutural e metamórfica desta província têm distinguido diferentes fases de deformação transpressiva e distensiva (Pinheiro \& Holdsworth 1997). Um exemplo de estrutura transpressiva é o Duplex da Serra Pelada (Lab \& Costa 1995). Efeitos da interferência do encurtamento horizontal regional com esforços ligados à colocação de plútons (Barros et al. 2001, Sardinha et al. 2006) têm sido identificados em rochas supracrustais. Segundo estes últimos autores, estes granitoides desenvolveram auréolas tectonotermais de fácies hornblenda/clinopiroxênio hornfels nas rochas metabásicas do Supergrupo Itacaiúnas.

Para Suita \& Nilson (1988), as rochas do Grupo Rio Novo teriam idade mínima de $2,76 \mathrm{Ga}$ e teriam sido metamorfisadas em condições de fácies anfibolito e xisto verde, com o grau metamórfico maior nas proximidades de granito-gnaisses. Esta informação será importante para as discussões feitas adiante. Segundo Suita \& Nilson (1988) o contato entre dioritos/ tonalitos/trondhjemitos atribuídos ao Complexo Xingu e as rochas metavulcano-sedimentares seria controlado por cavalgamentos. Diella et al. (1995) mencionam possíveis efeitos de metamorfismo dinâmico e termal em rochas supracrustais. Segundo Tallarico et al. (2001), dioritos $(>2,75 \mathrm{Ga})$ encontrados em testemunhos de sondagem seriam causadores de metamorfismo termal e, consequentemente, mineralizações nas rochas metacalcárias da Serra Pelada. Para Moroni et al. (2001) as rochas metavulcano-sedimentares da Serra Leste teriam sido cisalhadas e metamorfisadas em condições de médio e baixo grau entre 2,58 e 2,48 Ma.

\section{PETROGRAFIA E ESTRUTURA DE ROCHAS}

DA SERRA LESTE Nos domínios da Serra Leste, as rochas metabásicas predominam sobre as formações ferríferas/metacherts, sobre as rochas máficas-ultramáficas do Complexo Luanga e sobre os granitoides. As rochas metabásicas são cortadas por diques de diabásio de direção NS e por raros corpos de gabro de pequena dimensão (Fig. 2). As áreas com

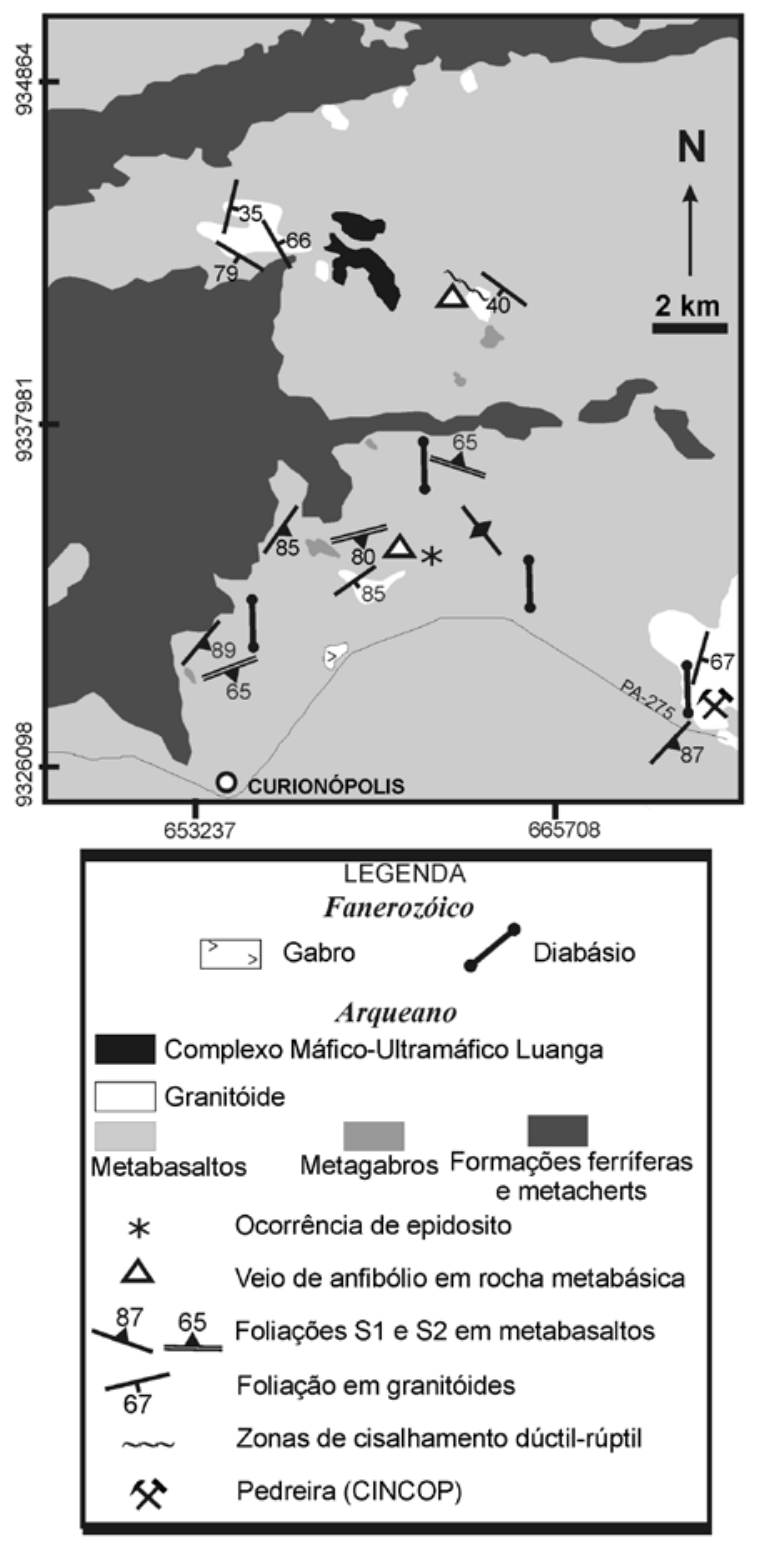

Figura 2 - Mapa litoestrutural da Serra Leste, Província Mineral de Carajás. 
exposição de rochas metabásicas e de granitoides são topograficamente arrasadas, comparativamente às faixas de formações ferríferas/metacherts que formam serras alongadas e ressaltadas no terreno. Estas faixas se concentram na parte centro-oeste e norte da área estudada e podem estar alinhadas na direção ENE/ WSW. Entretanto, nas proximidades de Curionópolis, estas faixas de formação ferrífera prolongam-se com direção NW/SE e tendem a amoldar-se aos limites do Complexo Granítico Estrela em suas partes nordeste, leste e sudeste, onde podem formar dobras suaves de interferência de grande dimensão (Barros et. al. 2001). Os corpos granitoides da Serra Leste são de pequenas dimensões e afloram sob a forma de lajedos descontínuos de dimensões variadas. Uma exposição de rochas granitoides, importante pela sua dimensão e pela qualidade com que se distinguem as estruturas, é representada pela pedreira CINCOP, no sudeste da área.

Rochas Metabásicas As rochas metabásicas de cor cinza escuro têm granulação fina e as de cor cinza médio granulação média a grossa (Fig. 3a). Estas rochas podem ter estrutura maciça ou apresentar foliações desenvolvidas em diferentes intensidades. As rochas de textura maciça mostram feições microtexturais primárias reliquiares, tais como as texturas subofítica, ofítica ou intergranular. Nestes casos, os cristais de plagioclásio são ripiformes e as formas originais dos cristais de opacos e de piroxênio são preservadas. Estes últimos foram substituídos por pseudomorfos de actinolita de cor verde pálido (Fig. 3b), resultando em uma textura blastofítica. Outra feição microscópica destas rochas é a parcial substituição das bordas da actinolita por hornblenda de cor verde oliva. Estas rochas são classificadas como metabasaltos e metagabros.

Em alguns afloramentos, as rochas metabásicas mostram uma foliação moderada, penetrativa na escala de afloramento, que é cortada por zonas de deformação de espessura decimétrica e de direção N70E. Nas proximidades dos contatos com alguns corpos granitoides, a rocha metabásica mostra foliação bastante desenvolvida e definida pela forte orientação preferencial de cristais de plagioclásio e hornblenda (Fig. 4). Em geral, as foliações dos anfibolitos são concordantes com as foliações dos granitoides adjacentes. Vênulas finas de plagioclásio podem estar dispostas paralelamente à foliação do anfibolito. Estas vênulas podem também exibir padrões escalonados ou irregulares. Nos domínios com forte venulação, é comum a presença de veios de espessura centimétrica e comprimento decimétrico preenchidos por cristais grossos de anfibólio. Estes veios assemelham-se aos descritos por Barros et al. (2002) em rochas metabásicas encaixantes do Complexo Granítico Estrela.

$\mathrm{Na}$ pedreira CINCOP, porções decimétricas de rocha metabásica, inclusas nos granitoides, apresentam estrutura maciça e textura granoblástica fina (Figs. 5a,b,c), definida pelo predomínio de finos cristais poligonais de clinopiroxênio, hornblenda verde oliva e verde acastanhada, além de plagioclásio
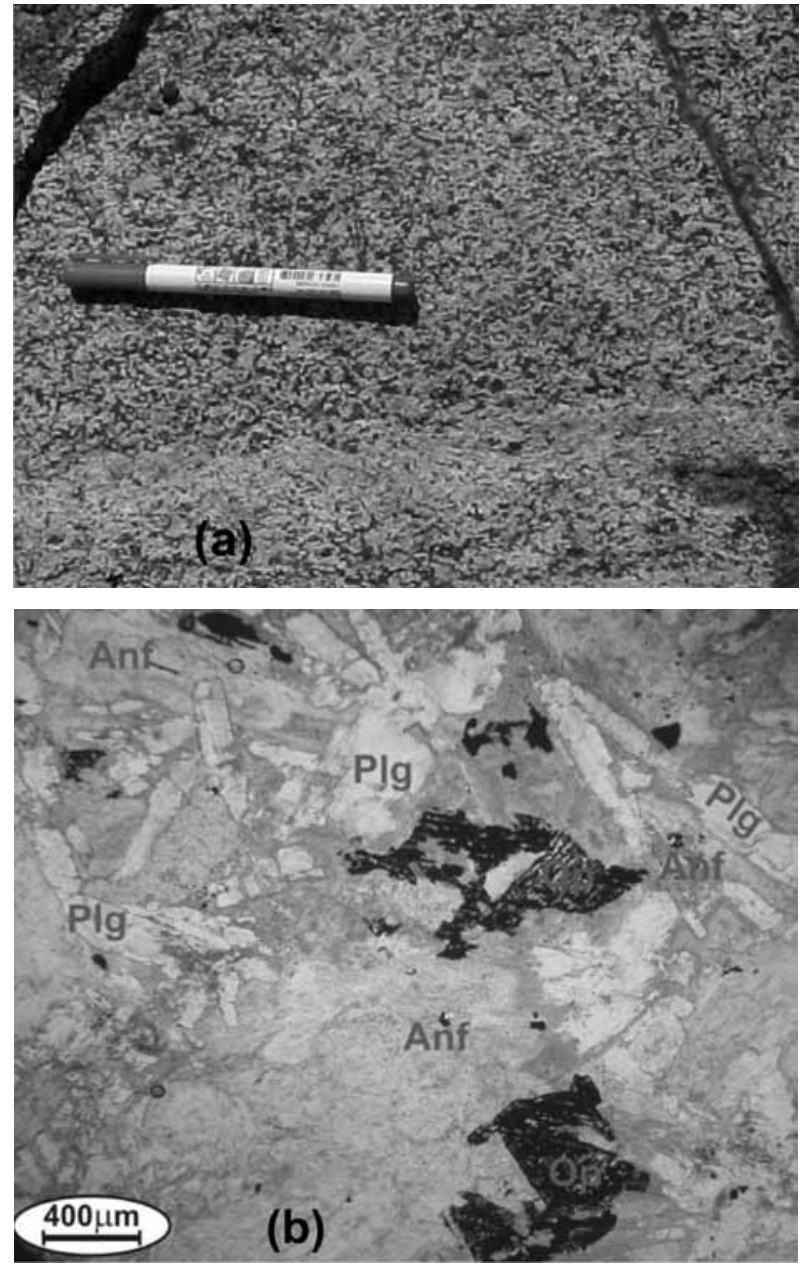

Figura 3 - a) Amostra de mão de metagabro. b) Fotomicrografia (luz natural) de metagabro da Serra Leste, mostrando textura ígnea preservada e pseudomorfos de actinolita com bordas de hornblenda.



Figura 4 - Afloramento de anfibolito com forte foliação $S_{2}$, Serra Leste, Província Mineral de Carajás. 
(An 47) límpido. A foliação do granitoide contorna as porções de rochas metabásicas (Fig. 5a). Essas feições estruturais juntamente com a textura granoblástica das rochas metabásicas permitem caracterizá-las como xenólitos. Alguns destes xenólitos são cortados por inúmeros veios aplíticos ou ainda mostram feições de parcial assimilação pelo granitoide. Nestes casos, os anfibolitos podem fragmentar-se em porções alongadas que amoldam-se à foliação do granitoide hospedeiro podendo dar origem a arranjos petrográficos complexos, simulando migmatitos. Quando o xenólito sofre digestão parcial pelo granitoide, desenvolve-se um incipiente acamamento composicional com padrão semelhante à estrutura schlieren.

Localizadamente, associadas aos metabasaltos, afloram rochas de cor verde escuro, constituídas por mais de $70 \%$ de epidoto, classificadas como epidositos, os quais possuem foliação algo homogênea de intensidade moderada a fraca.

Rochas granitoides $\mathrm{Na}$ área de estudo foram caracterizados três conjuntos de granitoides: 1) granitoides aflorantes na pedreira CINCOP; 2) granitoides aflorantes nas proximidades da Serra Pelada, denominados de Suíte Intrusiva Formiga (Tallarico et al. 2000); 3) um pequeno corpo situado na região centro-sul da área.

$\mathrm{Na}$ pedreira do CINCOP, afloram tonalitos, trondhjemitos e quartzo dioritos com acamamento primário definido pela presença de níveis de espessura decimétrica, relativamente ricos em minerais máficos, alternados com níveis algo mais leucocráticos (Fig. 5d). Este acamamento possui direção N20E e mergulhos subverticais. Uma foliação subparalela ao acamamento é marcada pela orientação preferencial moderada dos minerais máficos e pelo achatamento dos cristais de quartzo. Esta foliação pode contornar porções anfibolíticas (Fig. 5a). Estas foliações têm, por vezes, ondulações e dobras abertas. Falhas discretas de rejeito centimétrico são preenchidas por epidoto.

Nos domínios da Suíte Intrusiva Formiga afloram quartzo dioritos, tonalitos, granodioritos e monzogranitos. Estas rochas podem mostrar fraca foliação, marcada pela orientação preferencial de biotita
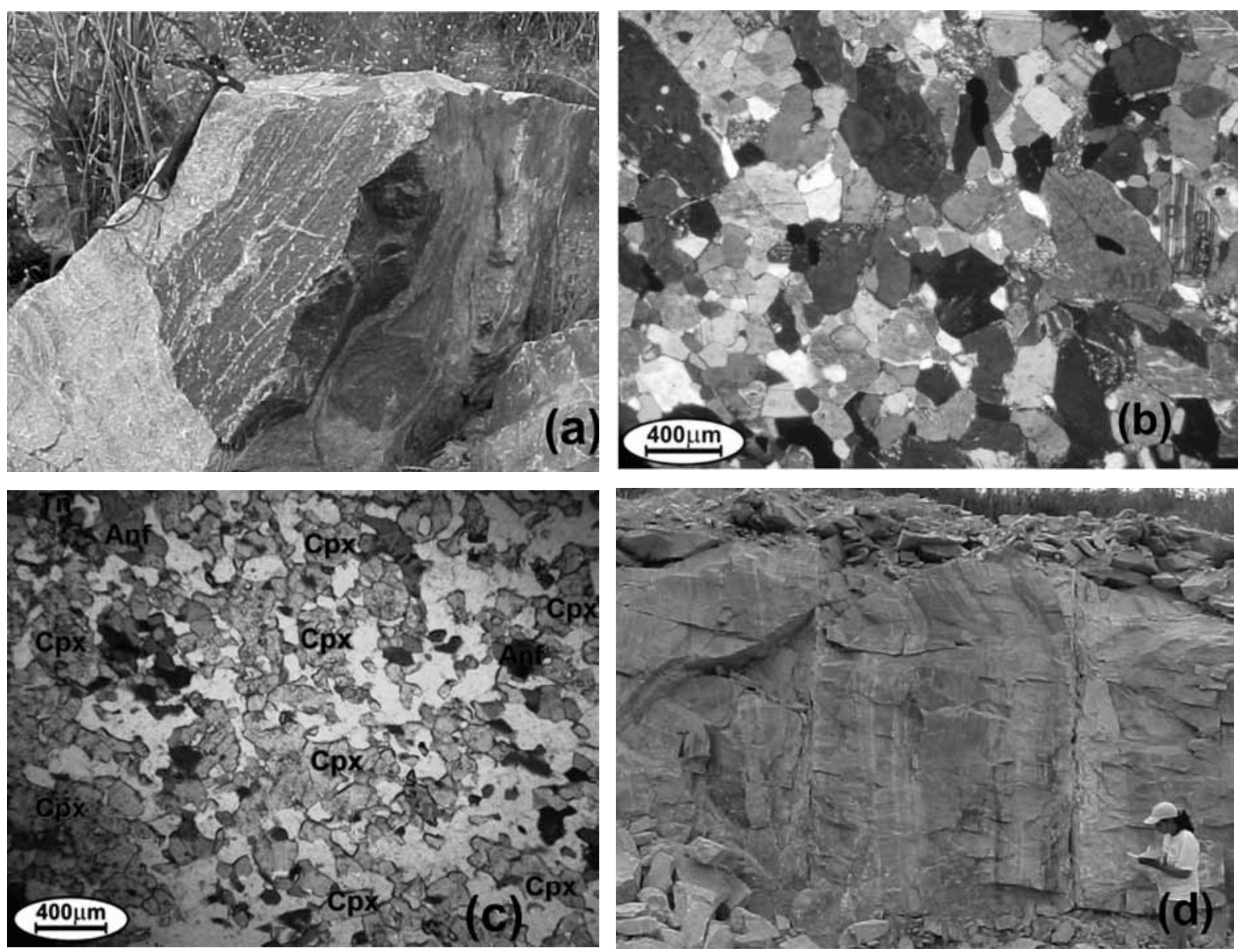

Figura 5 - a) Xenólito de rocha metabásica contornado pela foliação do granito. b) Fotomicrografia (luz polarizada) de anfibolito de fácies hornblenda hornfels. c) Fotomicrografia (luz natural) de xenólito anfibolítico de fácies clinopiroxênio hornfels. d) Granitoide da Serra Leste mostrando acamamento ígneo marcado pela alternância de bandas relativamente ricas em minerais máficos e bandas algo mais leucocráticas. 
e/ou anfibólio e pelo achatamento fraco a moderado de cristais quartzo. Em rochas porfiríticas de ocorrência localizada, a foliação pode ser delineada pela orientação preferencial de fenocristais pouco deformados de feldspato potássico. Esta foliação apresenta variações nas suas atitudes (N20W/66NE, N20E/35SE). Estas rochas localmente foram afetadas por zonas discretas de cisalhamento dúctil-rúptil N65W/40SW.

No pequeno corpo granítico do sul da área, situado a oeste da Pedreira CINCOP, as rochas têm cor cinza esbranquiçado, granulação fina a média e composição granodiorítica. A foliação (N70E/87SE) é moderada a fraca e definida pela fraca orientação preferencial dos raros cristais finos de biotita e pelo moderado achatamento de quartzo.

\section{Evolução Estrutural e Metamórfica da Serra} Leste A mudança textural das rochas metabásicas em associação com a natureza do zoneamento dos cristais de anfibólio tem sido empregada para reconstituir a história metamórfica de rochas de terrenos polimetamórficos (Cooper 1972, Laird \& Albee 1981). Particularmente na região de Carajás, estas características têm permitido entender a evolução metamórfica das rochas metabásicas encaixantes dos granitos Estrela, Igarapé Gelado e Serra do Rabo (Barros \& Barbey 1998, Barbosa 2005, Sardinha et al. 2006).

$\mathrm{Na}$ Serra Leste, as texturas subofíticas preservadas de rochas metabásicas hidrotermalizadas indicam a natureza estática da primeira fase de metamorfismo $\left(M_{0}\right)$. As paragêneses apontam para temperaturas de fácies xisto verde, zona de clorita ou biotita, resultantes muito provavelmente de alterações hidrotermais de ambiente marinho. Os epidositos teriam-se formado nesta fase, em resposta à forte interação de basaltos de fundo oceânico com a água do mar.

A segunda fase $\left(M_{1}\right)$ de metamorfismo, de natureza termal, causou modificações nas rochas metabásicas em condições de fácies hornblenda a clinopiroxênio hornfels, em resposta à colocação dos granitoides de 2,85 Ga da pedreira CINCOP. Os efeitos de deformação da sua auréola mais interna teriam sido somados aos esforços regionais, resultando em foliação $\mathrm{S}_{1}(\mathrm{~N} 20-30 \mathrm{E})$ nos metabasaltos, marcada pela incipiente orientação de anfibólio.

A terceira fase de metamorfismo $\mathrm{M}_{2}$, bastante localizada ao redor do corpo granítico do sul da área, ocorreu em condições de fácies hornblenda hornfels e teria ligação com efeitos térmicos daqueles granitos que, pela orientação do seu eixo maior próxima de EW, provavelmente são cronocorrelatos aos plútons neoarqueanos sintectônicos $(\sim 2,76 \mathrm{Ga})$ presentes na região. Ao longo dos contatos com estes granitos, os hornfelses da auréola interna apresentam foliação $\mathrm{S}_{2}$ (N70E). Em alguns afloramentos de anfibolitos, a foliação $S_{1}(\mathrm{~N} 30 \mathrm{E})$ é cortada pela foliação $\mathrm{S}_{2}(\mathrm{~N} 70 \mathrm{E})$, o que permite estabelecer a cronologia entre estas fases de deformação. O desenvolvimento da foliação $\mathrm{S}_{2}$ estaria relacionado aos efeitos de encurtamento regional segundo a direção N10E, somados aos esforços de expansão lateral daquele pequeno corpo granítico. Isto explica a pequena extensão lateral, da ordem de dezenas de metros em que a foliação $\mathrm{S}_{2}$ é impressa.

Veios de anfibólio e plagioclásio observados em hornfelses caracterizam a história de metamorfismo progressivo em rochas metabásicas previamente hidratadas. Nestas condições, é comum o aumento de pressão de fluidos provocado pelas reações de desidratação e consequente produção de fraturas hidráulicas e veios (Cesare 1994, Dutrow \& Norton 1995). Feições semelhantes têm sido observadas na aúreola interna dos plútons Estrela, Serra do Rabo e Igarapé Gelado (Barros et al. 2001, Sardinha et al. 2006, Barbosa 2005).

CONCLUSÕES Critérios estruturais observados em granitoides gnáissicos representados pelo caráter penetrativo da foliação na escala de afloramento, pela orientação de fenocristais fracamente deformados (Paterson et al. 1998), e pelo desvio da foliação em xenólitos anfibolíticos, evidenciam o caráter sintectônico destes granitoides. Logo, grande parte das feições dúcteis descritas em rochas granitoides da Serra Leste têm origem primária, ou seja, formaram no estágio magmático. Mobilizados quartzo-feldspáticos intercalam-se, por vezes, com os granitoides e cortam os xenólitos de rocha metabásica, o que origina arranjos litológicos complexos, em parte resultantes de mistura parcial de diferentes tipos de rochas que podem ser facilmente confundidos com migmatitos. A ausência de feições claras que indiquem processos de fusão parcial in situ não permite relacionar as estruturas daquelas rochas a efeitos de migmatização.

Há nítida variação no grau metamórfico das rochas metabásicas, fortemente controlada pela proximidade com corpos granitoides. Isto é demonstrado pela ocorrência de xenólitos de fácies clinopiroxênio hornfels e de rochas de fácies hornblenda hornfels nas auréolas internas. Estas condições são muito semelhantes àquelas estimadas por Tallarico et al. (2000) para o metamorfismo de rochas carbonáticas da Serra Pelada. A evolução metamórfica e a origem de veios de anfibólio em rochas metabásicas são muitos semelhantes ao que foi descrito nas rochas encaixantes do Complexo Granítico Estrela (Barros \& Barbey 1998, Barros et al. 2001, 2002). A particularidade do domínio da Serra Leste é a presença de rochas que sofreram duas fases de metamorfismo de contato acompanhadas de encurtamento, uma fase há ca. 2,85 Ga e a outra há ca. 2,75 Ga. Como o volume de granitoides de $2,85 \mathrm{Ga}$ nesta parte norte da Província Mineral de Carajás foi restrito, seus efeitos de metamorfismo de contato e de deformação de auréolas foram menores, em comparação aos mesmos processos da fase posterior $(\sim 2,75 \mathrm{Ga})$.

A idade de $2,85 \mathrm{Ga}$, anteriormente relacionada à migmatização de rochas da Serra Leste (Machado et al. 1991), é reinterpretada neste trabalho como sendo a idade de cristalização dos granitoides. Os efeitos termais em rochas metabásicas e a presença de xenólitos 
anfibolíticos em granitoides indicam que as sequências supracrustais arqueanas de Carajás (Supergrupo Itacaiúnas) são mais antigas que $2,85 \mathrm{Ga}$.

As rochas metabásicas, formações ferríferas e metacherts da Serra Leste têm continuidade física com as sequências supracrustais de Parauapebas, da Serra do Rabo e da Serra Sul. Além disto, há muitas características petrográficas e estruturais comuns às rochas supracrustais daqueles diferentes setores. Como consequência parece não ser indicada a subdivisão estratigráfica destas rochas em vários grupos (Igarapé Salobo, Igarapé Pojuca, Rio Novo). Os dados parecem confirmar a proposta de Araújo et al. (1988) no sentido de englobar na mesma unidade litoestratigráfica as rochas metavulcano-sedimentares da Província Mineral de Carajás, anteriores a 2,76 Ga.

Outro aspecto que cabe ser discutido diz respeito aos domínios que se estendem da Serra Leste em direção a oeste, ao longo do contato norte com o Complexo Granítico Estrela. Em muitos mapas geológicos regionais, estas áreas são cartografadas como pertencentes ao Complexo Xingu. Entretando, os dados petrológicos mostram que estes domínios são porções mais deformadas e metamorfisadas (auréola interna) da mesma série metavulcano-sedimentar.

Destas conclusões advêm algumas questões a serem resolvidas no futuro:

- as rochas metabásicas da Serra Leste seriam a extensão setentrional dos greenstones de Identidade e Sapucaia situados a sul no terreno Rio Maria-Xinguara?

- os terrenos setentrional (Serra dos Carajás) e meridional (Xinguara a Marajoara) já compunham uma mesma placa antes de $2,85 \mathrm{Ga}$ ?

Agradecimentos Este trabalho foi possível com o apoio institucional da Universidade Federal do Pará e de seu Instituto de Geociências e com os recursos financeiros da Companhia Vale e do Conselho Nacional de Desenvolvimento Científico e Tecnológico (554476/2005-3 - CT Mineral). O Primeiro autor agradece ao CNPQ pela bolsa de produtividade em pesquisa (306468/2009-3). A segunda autora agradece à Coordenação de Aperfeiçoamento de Pessoal de Nível Superior (CAPES) pela bolsa de estudo. Agradecemos aos editores da Revista Brasileira de Geociências pela oportunidade de divulgar nossos trabalhos. Somos gratos ao Prof. Dr. Rômulo Machado pela revisão detalhada do texto.

\section{Referências}

Althoff F.J., Barbey P., Boullier A.M. 2000. 2.8-3.0 Ga plutonism and deformation in the SE Amazonian craton: the Archean granitoids of Marajoara (Carajás Mineral Province, Brazil). Precambrian Research, 104:187-206.

Araújo O.J.B., Maia R.G.N., João X.S.J., Costa J.B.S. 1988. A Megaestruturação Arqueana da Folha Serra dos Carajás. In: SBG, Cong. Bras. Geol. Lat.- Amer. de Geol., 7, Belém, Anais p. 324-338.

Ashworth J.R. (ed.) 1985. Migmatites. Blackie, Glasgow, $302 \mathrm{p}$.

Barbosa J.P.O. 2005. Petrologia e estrutura de rochas granitoides da região do Salobo, Serra dos Carajás, Estado do Pará, Brasil. Dissertação de Mestrado, UFPA, Belém, $98 \mathrm{p}$.

Barros C.E.M. \& Barbey P. 1998. A importância da granitogênese tardi-arqueana $(2,5 \mathrm{Ga})$ na evolução tectono-metamórfica da Província Mineral de Carajás o Complexo Granítico Estrela e sua auréola de contato. Revista Brasileira de Geociências, 28(4):513-522.

Barros C.E.M., Barbey P., Boullier A.M. 2001. Role of magma pressure, tectonic stress and crystallization progress in the emplacement of the syntectonic A-type Estrela Granite Complex (Carajás Mineral Province, Brazil). Tectonophysics, 343:93-109.

Barros C.E.M., Barbey P., Costa Jr. P.R. 2002. Venulação e fraturamento hidráulico em rochas metabásicas encaixantes do Complexo Granítico Estrela, Província Mineral de Carajás. In: Klein E., Travassos L., Vasquez M. (eds.) Contribuição à Geologia da Amazônia. Belém, SBG-NO, 3:133-142.

Barros C.E.M., Sardinha A.S., Barbosa J.P.O., Macambira M.J.B., Barbey P., Boullier A.M. 2009. Structure,
Petrology, Geochemistry and zircon $\mathrm{U} / \mathrm{Pb}$ and $\mathrm{Pb} /$ $\mathrm{Pb}$ Geochronology of the Synkinematic Archean (2.7 Ga) A-type Granites from the Carajás Metallogenic Province, Northern Brazil. The Canadian Mineralogist, 47:1423-1440.

Bateman R. 1985. Aureole deformation by flattening around a diapir during in-situ ballooning: the Cannibal Creek granite. Journal of Geology, 93:293-310.

Cabral A.R., Lehmann B., Kwitko-Ribeiro R., Costa C.H.C. 2002. Palladium and Platinum Minerals from the Serra Pelada Au-Pd-Pt Deposit, Carajás Mineral Province, Northern Brazil. The Canadian Mineralogist, 40:14511463.

Cesare B. 1994. Synmetamorphic veining: origin of andalusite-bearing veins in the Vedrette di Ries contact aureole, Eastern Alps, Italy. Journal of metamorphic Geology, 12:643-653.

Cooper A.F. 1972. Progressive metamorphism of metabasic rocks from the Haast Schist Group of Southern New Zealand. Journal of Petrology, 13(3):457-492.

Costa J.B.S., Teixeira N.P., Pinheiro R.V.L., Bermerguy, R.L. 1990. Os sistemas estruturais transcorrentes do Cinturão Itacaiúnas na Região de Curionópolis, Leste do Estado do Pará. In: SBG, Cong. Bras. Geol., 35, Natal, Anais, 5:2345-2352.

Dall'Agnol, R., Teixeira, N.P., Rämö, O.T., Moura, C.A.V., Macambira, M.J.B. \& Oliveira, D.C. 2005. Petrogenesis of the Paleoproterozoic, Rapakivi, A-Type Granites of the Archean Carajás Metallogenic Province, Brazil. Lithos, 80:101-129.

Dias G.S., Macambira M.J.B., Dall'Agnol R., Soares A.D.V., Barros C.E.M. 1996. Datação de zircões de 
sill de metagabros: comprovação da idade arqueana da Formação Águas Claras, Carajás-Pará. In: SBG, Simp. Geol. Amaz., 5, Belém, Resumos Expandidos, p. 376379.

Diella V., Ferrario A., Girardi V.A.V. 1995. PGE and PGM in the Luanga mafic-ultramafic intrusion in Serra dos Carajás (Pará State, Brazil). Ore Geology Reviews, 9:445-453.

RIO DOCE GEOLOGIA E MINERAÇÃO (DOCEGEO). 1988. Revisão litoestratigráfica da província mineral de Carajás. In: CVRD/SBG, Cong. Bras. Geol., 35, Província Mineral de Carajás - Litoestratigrafia e principais depósitos minerais: Anexo aos anais, p.1159.

Dutrow B. \& Norton D. 1995. Evolution of fluid pressure and fracture propagation during contact metamorphism. Journal of metamorphic Geology, 13(6):677-687.

Gomes A.C.B. \& Dall'Agnol R. 2007. Nova associação tonalítica-trondhjemítica neoarqueana na região de Canaã dos Carajás: TTGS com altos conteúdos de Ti, Zr e Y. Revista Brasileira de Geociências, 37(1):182-193.

Hirata W.K., Rigon J.C., Kadekaru K., Cordeiro A.A.C., Meireles E.M. 1982. Geologia Regional da Província Mineral de Carajás. In: SBG, Simp. Geol. Amaz., 1, Belém, Anais, 1:100-110.

Lab K.O. \& Costa J.B.S. 1995. O Duplex Transpressivo Serra Pelada. Boletim do Museu Paraense Emílio Goeldi, 7:41-60.

Huhn S.B., Macambira M.J.B., Dall'Agnol R. 1999. Geologia e Geocronologia $\mathrm{Pb}-\mathrm{Pb}$ do Granito Alcalino Arqueano Planalto, Região da Serra do Rabo, Carajás - PA. In: SBG, Simp. Geol. Amaz., 6, Manaus, Anais., 1:463-466.

Laird J. \& Albee A.L. 1981. Pressure, temperature, and time indicators in mafic schist: their application to reconstructing the polymetamorphic history of Vermont. American Journal of Science, 281:127-175.

Leite A.A.S., Dall'Agnol R., Macambira M.J.B., Althoff F.J. 2004. Geologia e geocronologia dos granitoides arqueanos da região de Xinguara-PA e suas implicações na evolução do Terreno Granito-Greenstone de Rio Maria, Cráton Amazônico. Revista Brasileira de Geociências, 34(4):447-458.

Macambira M.J.B. \& Lafon J.M. 1995. Geocronologia da Província Mineral de Carajás; síntese dos dados e novos desafios. Boletim do Museu Paraense Emílio Goeldi, 7:263-288.

Machado N., Lindenmayer Z., Krogh T.H., Lindenmayer D. 1991. U-Pb geochronology of Archaean magmatism and basement reactivation in the Carajás area, Amazon shield, Brazil. Precambrian Research, 49:329-354.

Meireles E.M. \& Silva A.R.B. 1988. Depósito de ouro de Serra Pelada, Marabá, Pará. In: C. Schobbenhaus \& C.E.S. Coelho (eds.) Principais Depósitos Minerais do Brasil 3. Brasília, Departamento Nacional da Produção Mineral/Companhia Vale do Rio Doce, p. 547-557.

Moroni M., Girardi V.A.V., Ferrario A. 2001. The Serra Pelada Au-PGE deposit, Serra dos Carajás (Pará State,
Brazil): geological and geochemical indications for a composite mineralising process. Mineralium Deposita, 36:768-785.

Nogueira A.C.R., Truckenbrodt W., Pinheiro R.V.L. 1995. Formação Águas Claras, Pré-Cambriano da Serra dos Carajás: redescrição e redefinição litoestratigráfica. Boletim do Museu Paraense Emílio Goeldi, 7:177-277.

Olszewski W.J., Wirth K.R., Gibbs A.K., Gaudette H.E. 1989. The age, origin and tectonic of the Grão-Pará Group and associated rocks, Serra dos Carajás, Brazil: Archean Continental volcanism and rifting. Precambrian Research, 42:229-254.

Paterson S.R., Fowler Jr., T.K., Schmidt K.L., Yoshinobu A.S., Yuan E.S., Miller R.B. 1998. Interpreting magmatic fabric patterns in plutons. Lithos, 44:53-82.

Pidgeon R.T., Macambira M.J.B., Lafon J.M. 2000. Th-U$\mathrm{Pb}$ isotopic systems and internal structures of complex zircons from an enderbite from the Pium Complex, Carajás Province, Brazil: evidence for the ages of granulite facies metamorphism and the protolith of the enderbite. Chemical Geology, 166:159-171.

Pinheiro R.V.L. \& Holdsworth R.E. 1997. Reactivation of Archaean strike-slip fault systems, Amazon region, Brazil. Journal of the Geological Society of London, 154:99-103.

Pinheiro R.V.L. \& Holdsworth R.E. 1995. Significado Tectônico da Clivagem Transversa (Transecting Cleavage) em Dobras na Mina de Serra Pelada, Pará. Boletim do Museu Paraense Emílio Goeldi, 7:289-308.

Sardinha A.S., Barros C.E.M., Krymsky R. 2006. Geology, geochemistry and $\mathrm{U}-\mathrm{Pb}$ geochronology of the Archean (2.74 Ga) Serra do Rabo granite stocks, Carajás Metallogenetic Province, northern Brazil. Journal of South American Earth Sciences, 20:327-339.

Suita M.T.F. \& Nilson A.A. 1988. Geologia do complexo máfico-ultramáfico Luanga (Província de Carajás, Pará) e das unidades encaixantes. In: Cong. Bras. Geol., 35, Belém, Anais, p. 2813-2823.

Tassinari C.C.G. \& Macambira M.J.B. 2004. A evolução tectônica do Cráton Amazônico. In: Mantesso Neto V., Bartorelli A., Carneiro C.D.R., Neves B.B.B. (eds.) $O$ desvendar de um continente: a moderna geologia da América do Sul e o legado da obra de Fernando Flávio Marques de Almeida. São Paulo, Beca, p. 471-486.

Tallarico F.H.B., Coimbra C.R., Cravo Costa C.H. 2000. The Serra Leste sediment-hosted $\mathrm{Au}-(\mathrm{Pd}-\mathrm{Pt})$ mineralization, Carajás Province. Revista Brasileira de Geociências, 30:226-229.

Vasquez M.L. \& Rosa-Costa L.T. 2008. Geologia $e$ Recursos Minerais do Estado do Pará. Ministério de Minas e Energia, Secretaria de Geologia, Mineração e Transformação Mineral, Serviço Geológico do Brasil CPRM, Superintendência Regional de Belém, 328 p.

Manuscrito ID 13534

Submissão: 01 de março de 2009 Aceite em 23 de março de 2010 